\title{
Do uni-verso ao multi-verso: a relevância de Alfred Schütz para pesquisas no campo da Comunicação
}

\author{
Profa. Dra. Ulrike Schröder*
}

\begin{abstract}
RESUMO
No seu conceito de uma sociologia interpretativa, o sociólogo Alfred Schütz procura realizar uma análise profunda do nosso "mundo da vida" (Lebenswelt), partindo da conviç̧ão de que este mundo de sentido não representa uma realidade objetiva, mas sim, uma realidade interpretada e válida intersubjetivamente. Por isso, também não vivemos simplesmente em um uni-verso fixo, mas sim, em multi-versos, cada um marcado por um outro estilo epistemológico. O artigo apresenta as caracteristicas essenciais da teoria de Schütz, focalizando a atualidade do seu conceito, que indica possibilidades de tornar este fundamento teórico base para estudos empiricos no campo da comunicação hoje em dia.
\end{abstract}

Palavras-chaves: Mundo da vida, fenomenologia, multi-verso, estilo epistemológico, universos simbólicos

\section{ABSTRACT}

With his concept of an Interpretative Sociology, the sociologist and philosopher Alfred Schütz strives for a basic analysis of our life-world proceeding on the assumption that this world of means does not represent an objective reality, but always a reality already interpreted and intersubjectively valid. Therefore, we do not simply live in one persistent universe, but in multiple realities, and every single universe is characterized by its own epistemological style. The following anticle devotes to a presentation of the essential characteristics of Schütz' theory focussing on the actuality of his concept by indicating opportunities to turn this basic matrix of social world into a foundation for empirical studies in the field of communication today.

Key words: Life-world, phenomenology, multiple realities, epistemological styles, symbolic universes

\footnotetext{
* Professora visitante e leitora do DAAD (Serviço Alemão de Intercâmbio Acadêmico) na FALE e FAFICH (Pós-Graduação na Comunicação Social) da Universidade Federal de Minas Gerais (UFMG).
} 


\section{Introdução}

Com o intuito de investigar a realidade em que as pessoas vivem, por meio de uma perspectiva das Ciências Sociais, primeiro, impõem-se muitas perguntas quanto ao assunto focalizado: o que é realidade? De onde vem a idéia que nos faz considerar a realidade na qual vivemos como indiscutível? Como reconhecemos a realidade? Tais perguntas sempre foram objeto de pesquisas epistemológicas.

Em toda sua obra, Alfred Schütz, (1) tanto filosófica, quanto sociologicamente, concentra sua atenção na estrutura do mundo do sentido comum da vida cotidiana. Sua obra Der sinnhafte Aufbau der sozialen Welt. Eine Einleitung in die verstehende Soziologie, publicada pela primeira vez em 1932, faz uma alusão ao livro Der logische Aufbau der Welt (1928), escrito pelo positivista Rudolf Carnap. Mas Schütz escolhe outro ponto de partida. Com seu subtítulo Einleitung in die Verstehende Soziologie, ele refere-se à intenção de Max Weber que coloca outras premissas para as Ciências Sociais que não para as Ciências Naturais.

Com seu ponto de partida interpretativo, Schütz dá prosseguimento à fenomenologia transcendental do filósofo Edmund Husserl, Transzendentale Phänomenologie, transferindo-a à Sociologia, e a desenvolvendo. Com seu aluno Thomas Luckmann, Schütz publica a obra Strukturen der Lebenswelt. Mais tarde, em co-autoria com o sociólogo da religião Peter L. Berger, 202 Luckmann, por sua vez, lançou o tratado Die gesellschaftliche Konstruktion der Wirklichkeit, ("A construção social da realidade"), hoje em dia conhecido mundialmente, em que os autores, além de retomarem Schütz, recorrem à Sociologia do Conhecimento (Wissenssoziologie) de Max Scheler e Karl Mannheim.

Em seguida, serão apresentados os elementos básicos da teoria de Schütz, que, até hoje, tem grande influência nas Ciências Sociais. Depois disso, será focalizada a relevância do seu conceito dos multi-versos para estudos empíricos, especialmente hoje em dia, dentro do contexto de uma globalização crescente .

\section{A construção significativa do mundo social}

Fenomenologia significa a ciência das aparições (dos fenômenos). $O$ ponto de partida desta direção do pensamento não-racionalista e nãopositivista forma a hipótese de que um objeto necessariamente sempre seja referido a um sujeito assim que a realidade perde sua autonomia perante a consciência pura.

Para o filósofo Edmund Husserl, o mundo não é uma realidade que se permite descrever independentemente da vida e, por isso, somente é 
compreensivel em sua referência ao sujeito que experimenta o mundo como "Urstätte aller objektiven Sinnbildungen und Seinsgeltungen" (2) (origem de todas as formações e validades de significado), ou seja, a fenomenologia localiza a compreensão da realidade dentro da experiência das pessoas, e não pergunta pelas coisas por si, mas sim, por sua aparência.

Schütz segue esta idéia, e define o termo Lebenswelt como o conjunto de todas as realidades que o homem experimenta. (3) Ela representa uma realidade dada de forma indiscutível, e, sendo assim, é o centro enquanto objetivo das nossas ações, pelo fato de a encararmos por meio de uma atitude natural (natürliche Einstellung), como Husserl a chamou.

No entanto, para Schütz, não se trata de um mundo privado ou solipsista, mas sim, intersubjetivo e, com isto, social. Ele necessita de uma interpretação permanente dos indivíduos que atuam nele e para ele. Pois somente através de uma interpretação e de um aproveitamento dos meus acontecimentos passados e dos acontecimentos dos outros é que posso orientar-me no Lebenswelt e experimentar sentidos. Com isto, dentro da sua fenomenologia mundana (Mundanphänomenologie), Schütz afirma que a constituição do mundo começa com o ato da interpretação: não existem percepções sensitivas puras de um mundo externo, somente construções em que o objeto percebido se constitui:

All our knowledge of the world, in common-sense as well as in scientific thinking, involves constructs, i.e. a set of abstractions, generalizations, formalizations. idealizations specific to the respective level of thought organization. Strictly speaking, there are no such things as facts, pure and simple. All facts are from the outset facts selected from a universal context by the activities of our mind. They are, therefore, always interpreted facts $[\ldots]$ (4)

Assim, com vista ao mundo, Schütz fala de um já interpretado em que o homem, o "animal symbolicum", é nascido por dentro, e somente pode orientar-se "with the help of appresentational relations". (5)

Com este ponto de partida interpretativo, Schütz propõe um multiverso, ao invés de um uni-verso: como a existência depende basicamente da interpretação de sujeitos singulares, por consequêencia, também haverá tantas áreas de existência como haverá mundos de sentido gerados de forma interpretativa. Partindo desta premissa básica, Schütz descreve esses processos fundamentais que constituem o mundo, e apresenta um esboço de uma matriz universal do mundo socialmente feito que, por sua vez, oferece um quadro básico para pesquisas sócio-empíricas. 
Dentro dessa matriz universal, a natureza da realidade por excelência como realidade predominante (oberste Wirklichkeit) (6) da nossa vida cotidiana radica-se na perspectiva ego de cada indivíduo: dentro da perspectiva espacial e temporal, meu ambiente social delimita-se frente ao meu domínio da realidade social dos contemporâneos (Mitwelt) e ao meu domínio da realidade social dos predecessores (Vorwelt). (7) A estratificação temporal e espacial do mundo é impregnada por zonas de alcance atual, restabelecível ou obtenível (aktueller, wiederherstellbarer oder erlangbarer Reichweite). $\mathrm{O}$ mundo de alcance potencial abrange o mundo de alcance restabelecível com sua estrutura temporal do passado, assim como o mundo de alcance obtenível com sua estrutura temporal do futuro. (8) Esta vida cotidiana, Altagswelt, (9) na qual nós nos movimentamos todos os dias, nos é dada como inquestionável, não é posta em dúvida, e oferece uma pauta de certezas, cujo processo de criação não é questionado. Quem manifesta dúvidas sobre a natureza (So-Sein) da vida cotidiana, ou questiona suas certezas básicas com declarações como "Por que nós penduramos quadros nas paredes?", sem ficar cognitivamente dentro de um quadro do discurso científico, sem ser estrangeiro, ou ter três anos, poderá ser tido como louco. Uma das maiores certezas nesta vida cotidiana irrefutável forma a suposição de que a nossa realidade seja um mundo único e dividido intersubjetivamente: se trocarmos os pontos de vista, continua o mesmo.

Dentro de nossas experiências atuais, ou nós poderíamos viver puramente direcionados aos objetos dela, ou nós nos direcionaríamos às nossas experiências a partir de uma atitude reflexiva, e nos perguntaríamos a respeito do seu sentido. (10) Somente nesse segundo nível, a consciência registra o significado das suas experiências passadas sem sair do fluxo de consciência, delimitando um acontecimento de modo retrospectivo e, com isso, tirando-o do seu ambiente. Por conseguinte, o sentido não é inerente às experiências que fazemos per si, mas sim, apresenta uma interpretação préou pós-feita: seja como for, em todo o caso, apresenta uma interpretação reflexiva de uma experiência. (11) Nessa perspectiva, somente o vivido, sob a forma do experimentado, mas nunca a vivência por si, pode obter sentido assim que as fronteiras da lembrança também marcam as fronteiras do que é possível ser racionalizado (Rationalisierbarkeit). (12)

Quando o sentido é gerado durante o ato de se dirigir a atenção a uma vivência passada, mas, ao mesmo tempo, é ligado ao fluxo de consciência atual, deve haver modificações atencionais do significado (attentionale Modifikationen von Sinn) produzidas pelas mudanças contínuas do fluxo de consciência dependente do respectivo ponto de vivência dentro da minha consciência temporal linear no qual a significação é produzida; automaticamente, também o sentido atribuido é modificado continuamente. 
Porém, uma tal atribuição de sentido não se realiza em frente a um bastidor vazio, mas sim, sempre dentro de um horizonte intencional de fases de atividade mais tardias, sob a forma de um etcétera (Und-so-weiter): o presente cresce do passado, e já antecipa o futuro.

Em conformidade a isso, as nossas experiências nunca são isoladas e separáveis umas das outras, mas sim, aparecem o tempo inteiro num contexto de sentido dentro de um horizonte com orlas abertas (offenen Rändern): (14) dentro de um horizonte interior, a parte da frente da casa remete à sua traseira, a fachada ao interior, o telhado aos fundamentos invisíveis etc; dentro de um horizonte exterior, a árvore remete ao meu jardim, o jardim à rua, a rua à cidade etc. (15) Cada experiência a qual atribuímos um significado é definida também por seu horizonte: o que ouvimos, quando o trovão rebenta, por conseguinte, não representa o trovão puro, mas, sim, "thunder-breaking-upon-silenceand-contrasting-with-it". (16) Portanto, sentido sempre é dado com referência a outras coisas.

Como tais mundos de sentido, uma vez criados, são experimentados e reproduzidos? Para responder a essa questão, Schütz faz uma descrição do modo como a nossa vida cotidiana, o mundo de sentido mais indiscutivel, põe-se diante de nós, e aponta três dos seus traços fundamentais:

Unsere Alltagswelt ist von vornherein intersubjektive Kulturwelt: intersubjektiv, weil wir als Menschen unter anderen Menschen in ihr leben, mit ihnen verbunden zum gemeinsamen Wirken und Werken, andere versiehend und anderen zum Verständnis aufgegeben; Kulturwelt, weil uns die Lebenswelt von vornherein ein Universum von Bedeutsamkeiten ist, von Sinnzusammenhängen, die wir zu deuten haben, und von Sinnbezügen, die wir erst durch unser Handeln in dieser Lebensumwelt stiften; Kulturwelt auch deshalb, weil wir uns ihrer Geschichtlichkeit immer bewußt sind, einer Geschichtlichkeit, die uns in Tradition und Habitualität entgegentritt und befragbar ist, weil alles Fertig-Vorfindliche auf eigene oder fremde Aktivität rückverweist, deren Sediment es ist. (17)

Desde o princípio, a nossa vida cotidiana representa um mundo de cultura intersubjetivo, já que vivemos nele como homens junto com outros homens, ligados nele, realizando trabalhos em conjunto, compreendendo os outros, e fazendo os outros nos compreender; mundo de cultura porque, desde o princípio, o Lebenswelt representa um universo de significados, de contextos de sentido que devemos interpretar, e de relações de sentido que 
criamos somente através de nossas ações nesse Lebenswelt; mundo de cultura, também, porque sempre estamos conscientes da sua historicidade, uma historicidade que nos enfrenta pela tradição e pelos costumes e que é questionável pelo fato de que todas as coisas encontradas de forma feita remetem-se às suas próprias atividades ou àquelas de um outro das quais elas são uma sedimentação.

Esta citação não somente faz uma alusão ao caráter intersubjetivo e à determinação cultural da realidade, mas sim, também, à dependência histórica da vida cotidiana. Nisso, Schütz fala da sedimentação (Sediment), um termo que ele recebeu de Husserl. Este último vê na história "die lebendige Bewegung des Miteinander und Ineinander von ursprünglicher Sinnbildung und Sinnsedimentierung" (o movimento vivo do conjunto e da engrenagem da formação de sentido original e da sedimentação de sentido). (18) Com o tempo, as comunidades de cultura diferentes do mundo objetivam kommunikative Gattungen (gêneros comunicativos), e formam Sinnsetzungstraditionen (tradições de criação de sentido), (19) que, por sua vez, contribuem para camadas da realidade de acordo com o ponto de vista. Tais tradições da criação dos sentidos baseiam-se na institucionalização e em atos repetidos que servem para que não haja a necessidade de se redefinirem objetivos e motivos sempre novamente, pois são recorrências já comprovadas.

Essas instituições, guias de comportamento, receitas cotidianas, ou padrões de papéis como respostas tipificadas a perguntas também tipificadas, sobretudo, são resultados de processos comunicativos. Por meio da língua, podem-se abstrair do momento 'here and now' esferas da realidade separadas em contextos de sentido e, ainda, criar relações superiores:

In this way, my biographical experiences are ongoingly subsumed under general orders of meaning that are both objectively and subjectively real. Because of its capacity to transcend the 'here and now', language bridges different zones within the reality of everyday life and integrates them into a meaningful whole. The transcendences have spatial, temporal and social dimensions. (20)

Dessa maneira, todas as coisas que nós experimentamos têm um lugar no universo simbólico e obtêm significado. (21) Assim, religião, economia, literatura ou ciência compreendem campos semânticos: objetivações que oferecem significados para acontecimentos decorrentes, e que, em sua especificidade em respectivos esquemas de ordenação, se delimitam dos outros universos simbólicos. 
Com complexidade crescente, essa rede lingüística também produz "second-order objectivations of meaning", (22) mecanismos conceituais da manutenção, (como mitos ou teorias científicas), cujas tarefas são explicar e justificar instituições. Portadores de tais conceitos de apoio como, por exemplo, o Shamã, o sacerdote ou o cientista que dão respostas a perguntas críticas, são especialistas, de acordo com a respectiva visão do mundo de uma cultura. Paralelamente, nascem papéis para a legitimação de papéis, como aqueles dos economistas que, por exemplo, vendem para nós o monopólio de conhecimento das análises e previsões econômicas, assim como a credibilidade da respectiva instituição. (23)

Com tudo isso, universos simbólicos como "matrix of all socially objectivated and subjectively real meanings" (24) trazem ordem à vida das pessoas e ao todo social. Pessoas divergentes que causam caos são sancionadas por medidas coercitivas, diretas ou sutis, como prisão, desterro ou exclusão da respectiva comunidade. Nesse contexto, parece interessante que, dentro de nossas sociedades, cada vez mais complexas e globais, encontrem-se, progressivamente, indivíduos que neguem alguns desses modelos do Lebenswelt e, em lugar disso, prefiram outros contextos de sentido do mundo, e formem, por conseqüencia, comunidades específicas como uma subcultura como o movimento Hip Hop ou uma seita religiosa. É certo que a pessoa desviante vive, numa tal comunidade, uma realidade alternativa, exclusivamente válida para ela, embora ela se mova dentro do quadro significativo do Lebenswelt superior. O satanista, por exemplo, que é ao mesmo tempo agente financeiro, pode agir segundo os contextos significativos da economia, e ser, no sentido profissional, completamente integrado à sociedade. As comunidades desviadas da realidade formam ilhas de realidades estrangeiras no meio da realidade geral e objetivamente válida: elas transcendem partes do Lebenswelt, mas, todavia, de forma nenhuma, são soltas das suas estruturas e dos seus princípios de conteúdo de modo geral.

Enfim, experiências que foram colocadas em diversas esferas da realidade são integradas num mundo de sentido superior com ajuda de atribuições de sentido superiores. Assim, é certo que a nossa vida se passa em vários palcos: no universo do trabalho, na familia, no ambiente de amigos, no clube de tênis e no movimento popular etc; não obstante, criamos um conceito de vida superior, uma biografia que guarda em conjunto todas as esferas distintas e atribui a elas um sentido total. Aí, seria necessário perguntar até que ponto o homem ainda consegue realizar isso diante do nosso mundo globalizado em que relações de sentido fixas cada vez mais se deterioram.

\section{Panorama: A análise do "Lebenswelt" segundo Schütz como ponto de partida para pesquisas empíricas no campo da Comunicação}


O multi-verso que Schütz coloca no lugar do universo forma ponto de partida para sua análise sobre as realidades diferentes no artigo "On Multiple Realities". (25) Apoiando-se no psicólogo e filósofo norte-americano William James, Schütz define a realidade atualmente dada como horizonte de sentido que aparece e desaparece junto com a atenção: (26)

Each world whilst it is attended to is real after its own fashion; only the reality lapses with the attention. (27)

Se a realidade se constitui através da forma específica como o homem se direciona às coisas, ela nasce na maneira da sua atitude perante as coisas. Portanto, mudanças na atitude cognitiva mudam o mundo também. Nesse momento, o homem adentra em uma área de sentido nova, em que predomina um outro estilo epistemológico. Nesse ponto, as áreas de sentido de Schütz são fechadas. Portanto, apenas minha atitude cognitiva, e não minha mudança espacial, é decisiva para o experimentar em e através de diversas realidades. $O$ homem pode experimentar mais do que apenas uma realidade no mesmo espaço. Um exemplo par excellence seriam os cada vez mais númerosos mundos virtuais. Schütz chama o momento de uma tensão de atenção a outra como "pulo" ou "choque": depois de ter acordado, preciso voltar a mim, depois do final de um filme mostrado no cinema, preciso adaptar-me à luz ofuscante da sala novamente, depois de uma noite de festa, preciso tomar uma aspirina para ver claramente de novo. Enquanto o homem anda entre os seus estilos epistemológicos, no campo de conteúdo, ao mesmo tempo, também mudam os contextos significativos constituídos intersubjetivamente.

Então, poderia ser falado de uma mudança das relevâncias de conteúdo, do tempo da vivência, da tensão da atenção, assim como dos significados:

In verschiedenen Welten ist Verschiedenes wahr. Em mundos diferentes, coisas diferentes são verdades.

A respectiva realidade reflete-se em uma própria língua. Obedecendo às gramáticas cotidianas, esta torna-se sistema de apresentações simbólicas, impregnadas por palavras e expressões idiomáticas exclusivamente válidas no respectivo universo simbólico. Assim, a língua cria semânticas que refletem e manifestam a respectiva realidade. Um exemplo seria o mundo de um quartel militar, no qual designações de patente como "primeiro-sargento" estabelecem hierarquias dentro da comunicação, e onde atos de fala, como "retirar-se", referem-se a contextos de sentido especiais e constróem uma realidade no quartel a partir de um comportamento não-verbal, rigorosamente normalizado e ritualizado. 
Ao contrário dessa realidade séria, também há realidades não-sérias que estão fora do cotidiano, como construçōes sociais ou subjetivas sem conseqüências na vida cotidiana: espaços de ilusões ou universos do prazer. Uma análise interessante de tais universos de prazer foi feita pela especialista em comunicação Claudia Schirrmeister em sua pesquisa "Schein-Welten im Alltagsgrau. Über die soziale Konstruktion von Vergnügungswelten" ("Mundos brilhantes no cotidiano cinza. Sobre a construção social dos mundos de prazer"). (29) A autora ilustra a atualidade dos fundamentos sociológicos de Alfred Schütz partindo da hipótese de que mundos de prazer oferecem um abandono das exigências do cotidiano que é legitimado socialmente por ele próprio. Enquanto a quebra ou o desrespeito das premissas e relevâncias cotidianas, geralmente, são sancionados rigorosamente, os mundos de prazer, nem poucas vezes, são produtos programados feitos ou pelo menos justificados pelo mundo cotidiano. (30) Em seguida, Schirrmeister diferencia entre heterotopias passivas como cinema, teatro, concerto, em que a realidade específica se constitui de modo subjetivo, e heterotopias ativas como jogos, festas, clubes de férias, bordéis, discotecas ou mundos de cyberspace, que respresentam mundos sociais e desenvolvem sociedades "como-se-fosse".

Um outro exemplo que mostra a capacidade de realizar uma ánalise profunda do nosso mundo da vida a partir das premissas de Schütz seria a transferência da arquitetura do Lebenswelt, assim como das suas implicações metodológicas, às pesquisas interculturais. Partindo das construções que são responsáveis pela criação da vida cotidiana, Schütz afirma que também as ciências não têm nenhum acesso privilegiado à realidade. Ele fala das construções de segundo grau para realçar que não se trata de declarações que são feitas de um ponto de referência externo, mas, sim, cujas raízes têm que ser procuradas na vida cotidiana. A pesquisa recente "Brasilianische und deutsche Wirklichkeiten - eine vergleichende Fallstudie zu kommunikativ erzeugten Sinnwelten" ("Realidades brasileiras e alemãs - um estudo comparativo sobre universos de sentido gerados de forma comunicativa"), (31) que analisa conceitos significativos baseados em atos comunicativos no Brasil e na Alemanha, baseia-se nessa diferenciação que propõe que cada método que deve servir para uma investigação de conceitos significativos de uma cultura ou subcultura, primeiramente, tem que se direcionar à perspectiva do perguntado. Como Schütz formulou claramente, numa superação da perspectiva objetivista, a pergunta central teria que passar da pergunta "O que o mundo social significa para o observador?" para a pergunta "O que o mundo social significa para o ator observado dentro desse mundo, e o que ele mesmo quis dizer com sua atividade nele?":

The safeguarding of the subjective point of view is the only but sufficient guarantee that the world of social 
reality will not be replaced by a fictional non-existing world constructed by the scientific observer. (32)

Assim, as perguntas dos questionários desse estudo de campo comparativo, assim como as entrevistas, foram fundados neste procedimento qualitativo: foram elaboradas perguntas abrangantes como, por exemplo, "O que significa família para você?" para as pessoas darem respostas dissertativas a partir das quais poderia ser feita uma análise dos conceitos, metáforas, estruturas etc. divergentes. Além disso, a concepção dos questionários, assim como das entrevistas realizadas no Brasil e na Alemanha, foi apoiada na arquitetura do conceito Lebenswelt de Schütz: a vida cotidiana foi dividida em sub-universos significativos como família, relação amorosa, amizade, trabalho, universidade. O sentimento temporal foi registrado a partir das perguntas sobre a constituição da própria biografia (passado - presente - futuro). As relações com os outros, e com isso também o espaço de percepção, foram subdivididos em: ambiente social, domínio da realidade social dos contemporâneos e domínio da realidade social dos predecessores. No centro da pesquisa, encontrou-se uma comparação entre Alemanha e Brasil, considerando a estruturação simbólica feita desses universos significativos pelos entrevistados.

\section{NOTAS}

(1) Alfred Schütz nasceu em 1899 em Viena. Lá, depois de terminados os seus estudos em Direito, Economia e Sociologia, trabalhou num banco. Entretanto, ao mesmo tempo, continuou se dedicando muito à Sociologia e estudou Husserl, Parsons, Simmel, Scheler e Weber. Em 1937, emigrou aos Estados Unidos. A partir de 1943, começou a ensinar na New School of Social Research, em Nova Iorque, onde se encontravam muitos emigrantes europeus. Lá, em 1952, tornou-se professor de Sociologia, e de Psicosociologia. Morreu em 1959 , em Nova Iorque.

(2) Cf. Husserl 1972: p. 102.

(3) Cf. Schütz/Luckmann 1975:p. 41. A isto, portanto, pertencem as realidades do sonho (oníricas), religiosas, artísticas etc.

(4) Cf. Schütz 1973: p. 5.

(5) Cf. Schütz 1973:p. 356.

(6) Cf. Schütz 1973: p. $218 \mathrm{~s}$.

(7) O ponto zero do meu sistema de coordenadas do qual eu ordeno esferas de realidade diferentes é meu Aqui e Agora. Portanto, as coisas são classificadas em referência ao meu corpo através das categorias direita e esquerda, em frente e atrás, em cima e embaixo, perto e longe assim como em referência à perspectiva temporal antes e depois; cf. Schütz 1971a: p. 255. 
(8) Na sua reflexão sobre a estrutura temporal, Schütz recorre a Husserl; cf. Schütz 1973: p. 284s e Schütz 1993: p. 66.

(9) Na transição da fenomenologia transcendental de Husserl, passando pela fenomenologia constitutiva de Schütz, até a fenomenologia cotidiana de Berger/Luckmann, a noção de Welt muda-se (transforma-se) do abstrato ao concreto: Lebenswelt (Husserl) '! Sozialwelt (Schütz) '! Alltagswelt (Schütz e Berger/Luckmann).

(10) Cf. Schütz 1993: p. 62. Com a distinção dessas duas esferas de vivência, Schütz recorre a Bergson, que opõe o viver simples, dentro do fluxo de consciência como tornar e sumir, contínuo de qualidades potencialmente múltiplas, à vida dentro do mundo abstrato de tempo e espaço, com seu tempo homogêneo, especializado, descontínuo, e quantificável; cf. Bergson 1889.

(11) Cf. Schütz 1973:p. 210.

(12) Cf. Schütz 1993: p. 69.

(13) Cf. Schütz 1993: p. 96ss.

(14) O termo Ränder (fringes) foi introduzido por James; cf. James 1950a: p.258ss.

(15) Os termos do inneren e äußeren Horizontes (horizonte interior exterior) remontam a Husserl; cf. Husserl 1972: p. 26ss.

(16) Cf. James 1950a: p. 240.

(17) Cf. Schütz 1971a: p. 155.

(18) Cf. Husserl 1976: p. 380.

(19) Cf. Schütz/Luckmann 1984: p. 13.

(20) Cf. Berger/Luckmann 1967: p. 54.

(21) Cf. Berger/Luckmann 1967:p. 54ss.

(22) Cf. Berger/Luckmann 1967: p. 110.

(23) Cf. Berger/Luckmann 1967: p. 89ss.

(24) Cf. Berger/Luckmann 1967: p. 114.

(25) Cf. Schütz 1971 a. Schütz recebe o conceito das realidades múltiplas dos "sub-universa of reality" de William James; cf. James 1950b: p. 292s. Com isso, James refere-se a mundos como religião, mitologia, ou literatura. Porém, na teoria de Schütz, esses mundos de sentido obtêm um caráter mais intersubjetivo.

(26) Cf. Schütz 1973: p. 207s.

(27) Cf. James 1950b: p. 293a.

(28) Cf. Goodman 1984: p. 31.

(29) Cf. Schirrmeister 2002.

(30) Cf. Schirrmeister 2002: 55ss.

(31) Cf. Schröder 2003

(32) Cf. Schütz 1971 b: p. 8. Ao mesmo tempo, dentro da Antropologia e da Etnologia, também se observa uma discussão metodológica sobre o procedimento correto do etnólogo. O etnólogo britânico Bronislaw Malinowski 
explicita esse problema na sua concepção do observador participante, opondo-o ao procedimento objetivista: "The goal is, briefly, to grasp the native's point of view, his relation to life, to realise his vision of his world." (cf. Malinowski 1978: p. 25). Desde então, exigências semelhantes encontramse sempre de novo para a pesquisa sócio-empírica; cf. a exigência de uma perspectiva "êmica" em vez de uma "ética" dentro da Etnografia da Comunicação (cf. Pike 1971: p. 25ss), a exigência de uma descrição densa em lugar de uma superficial na Antropologia Semiótica (cf. Geertz 1973:p. 20ss) ou a exigência de uma perspectiva comunicativa ao invés de uma extracomunicativa na Comunicação Social (cf. Ungeheuer 1972: p. 37ss).

\section{Referências bibliográficas}

BERGER, Peter L./LUCKMANN, Thomas. "The Social Construction of Reality. A Treatise in the Sociology of Knowledge". London, Allen Lane The Penguin Press 1967.

BERGSON, Henri. "Essai sur les données immediates de la conscience". Paris, F. Alcan 1889.

GEERTZ, Clifford. "The Interpretation of Cultures". Selected Essays by Clifford Geertz.New York, Basic Books, Inc. 1973.

212 GOODMAN, Nelson. "Weisen der Welterzeugung". Frankfurt am Main, Suhrkamp 1984.

HUSSERL, Edmund. "Husserliana: Gesammelte Werke". Band VI. Die Krisis der Europäischen Wissenschaften und die Transzendentale Phänomenologie. Eine Einleitung in die Phänomenologische Philosophie. Hg. von Walter Biemel. Den Haag. Martinus Nijhoff 1976.

HUSSERL, Edmund. "Erfahrung und Urteil". Untersuchungen zur Genealogie der Logik.

Hamburg. Felix Meiner Verlag 1972.

JAMES, William. "The Principles of Psychology". Volume One. New York, Dover Publications 1950a.

JAMES, William. "The Principles of Psychology". Volume Two. New York: Dover Publications 1950b.

LAMNEK, Siegfried. “Qualitative Sozialforschung”. Band 1. Methodologie. Weinheim, Psychologie Verlags Union 1995.

MALINOWSKI, Bronislaw. "Argonauts of the Western Pacific". An Account of Native 
"Enterprise and Adventure in the Archipelagoes of Melanesian New Guinea". London, Henley, Routledge \& Kegan Paul 1978.

PIKE, Kenneth L. "Language in Relation to a Unified Theory of the Structure of Human Behavior". The Hague, Paris, Mouton \& Co. 1971.

SCHIRRMEISTER, Claudia. "Schein-Welten im Alltagsgrau. Über die soziale Konstrukti-on von Vergnügungswelten". Wiesbaden, Westdeutscher Verlag 2002.

SCHRÖDER, Ulrike. "Brasilianische und deutsche Wirklichkeiten". Eine vergleichende Fallstudie zu kommunikativ erzeugten Sinnwelten. Wiesbaden, Deutscher Universitätsverlag 2003.

SCHÜTZ, Alfred. "Der sinnhafte Aufbau der sozialen Welt". Eine Einleitung in die Verstehende Soziologie. Frankfurt am Main, Suhrkamp 1993.

SCHÜTZ, Alfred. "Collected Papers I. The Problem of Social Reality". The Hague, Martinus Nijhoff 1973.

SCHÜTZ, Alfred. "Gesammelte Ausätze 1. Das Problem der sozialen Wirklichkeit". Den Haag, Martinus Nijhoff 1971 a.

SCHÜTZ, Alfred. "Collected Papers II. Studies in Social Theory". The Hague, Martinus Nijhoff 197lb.

SCHÜTZ, Alfred/LUCKMANN, Thomas. "Strukturen der Lebenswelt". Neuwied, Luchter-hand 1975.

SCHÜTZ, Alfred/LUCKMANN, Thomas. "Strukturen der Lebenswelt". 2. Band. Frankfurt am Main, Suhrkamp 1984.

UNGEHEUER, Gerold. "Sprache und Kommunikation". Hamburg, Helmut Buske Verlag 1972. 


\section{Centracampo"}

214 